\title{
Uterine cervical squamous cell carcinoma without p16 (CDKN2A) expression: Heterogeneous causes of an unusual immunophenotype
}

\section{AUTHOR(S):}

Rokutan-Kurata, Mariyo; Minamiguchi, Sachiko; Kataoka, Tatsuki R.; Abiko, Kaoru; Mandai, Masaki; Haga, Hironori

\section{CITATION:}

Rokutan-Kurata, Mariyo ...[et al]. Uterine cervical squamous cell carcinoma without p16 (CDKN2A) expression: Heterogeneous causes of an unusual immunophenotype. Pathology International 2020, 70(7): 413-421

\section{ISSUE DATE:}

2020-07

URL:

http://hdl.handle.net/2433/254475

\section{RIGHT:}

This is the peer reviewed version of the following article: 'Pathology International' 70(7) 413-421, which has been published in final form at https://doi.org/10.1111/pin.12930. This article may be used for non-commercial purposes in accordance with Wiley Terms and Conditions for Use of Self-Archived Versions.; The full-text file will be made open to the public on 17 April 2021 in accordance with publisher's 'Terms and Conditions for Self-Archiving'.; This is not the published version. Please cite only the published version.; この論文は出版社版でありません。引用の際には出版社版 をご確認ご利用ください。 
1 Uterine cervical squamous cell carcinoma without p16 (CDKN2A) expression:

2 Heterogeneous causes of an unusual immunophenotype

3

4 Short running title:

5 p16-negative uterine cervical SCC

6

7 Authors:

8 Mariyo Rokutan-Kurata, MDㄹ, Sachiko Minamiguchi, MD, PhD ${ }^{1}$, Tatsuki R Kataoka,

$9 \mathrm{MD}, \mathrm{PhD}^{1}$, Kaoru Abiko, MD, $\mathrm{PhD}^{2,3}$, Masaki Mandai, MD, PhD², Hironori Haga, MD, $10 \mathrm{PhD}^{1}$.

11

121 Department of Diagnostic Pathology, Kyoto University Hospital, 54 Shogoin 13 Kawahara-cho, Sakyo-ku, Kyoto, 606-8507, Japan

14 Tel: $+81-75-751-3488$

$15{ }^{2}$ Department of Gynecology and Obstetrics, Kyoto University Hospital, 54 Shogoin

16 Kawahara-cho, Sakyo-ku, Kyoto, 606-8507, Japan

17 Tel: +81-75-751-3269

$183^{3}$ Department of Gynecology and Obstetrics, National Hospital Organization Kyoto

19 Medical Center, 1-1 Fukakusamukaihata-cho, Fushimi-ku, Kyoto, 612-0861, Japan

20 Tel: +81-75-641-9161 


\section{Abstract}

2 Immunohistochemically p16 (CDKN2A)-negative uterine cervical squamous cell

3 carcinoma (SCC) is uncommon, and there are few reports about its pathological

4 features. This study explored the causes of p16 negativity in such cases. We

5 analyzed diagnostic tissue samples of 5 cases of p16-negative cervical SCC among

6107 patients who underwent hysterectomy at Kyoto University Hospital between

7 January 2010 and December 2015. The samples were subjected to

8 immunohistochemical staining, in situ hybridization, and a genetic analysis. Two of

9 five cases were positive for HPV by genotyping. One was positive for HPV56 with

10 promoter hypermethylation of $C D K N 2 A$ and co-existing Epstein-Barr virus infection.

11 Another was positive for HPV6 categorized as low-risk HPV with condylomatous

12 morphology. Among the remaining three cases, one had amplification of the L1 gene

13 of HPV with promoter hypermethylation of CDKN2A and TP53 mutation, and one of

14 the other two HPV-negative cases had a homozygous CDKN2A deletion, while the

15 other was positive for p53 and CK7. p16-negativity of cervical SCC is often

16 associated with an unusual virus infection status and CDKN2A gene abnormality.

Key words: p16, human papilloma virus, uterine cervical squamous cell carcinoma 


\section{Introduction}

2 Most uterine cervical squamous cell carcinomas (SCCs) are caused by persistent

3 high-risk human papilloma virus (HPV) infection, ${ }^{1-3}$ and the treatment strategy for

4 squamous intraepithelial lesions (SILS) is based on both the histological diagnosis

5 and an HPV typing test. The aberrant overexpression of p16 (CDKN2A) is recognized

6 as a characteristic feature of HPV-related cancers among uterine cervical and

7 oropharyngeal SCC. ${ }^{4,5}$ This elevation of the p16 levels in HPV-related cancer and its

8 precursors is caused by the constant inactivation of RB by the E7 protein of high-risk

9 HPV. Loss of the RB function leads to the release of transcription factors, such as

10 E2F1, and results in the overexpression of $\mathrm{p} 16 .^{6}$

11 Regarding uterine cervix, continuous strong nuclear and cytoplasmic staining

12 for at least one-third of the epithelial thickness suggests HPV-related precancerous

13 lesions, ${ }^{7}$ and the use of p16 immunostaining is recommended for distinguishing

14 between cervical dysplasia and its mimics. The frequency of p16 expression in cervical SCC is about $83.5 \%-100 \% .^{8,9}$ However, cervical SCCs that are negative for

16 p16 have not been extensively studied. The histological features and HPV infection

17 status as well as the detection methods applied vary among evaluated lesions, and

18 how SCCs are negative for p16 remains unclear. ${ }^{10-15}$ 
2 infection, the CDKN2A, and TP53 mutation status as well as other staining findings

3 (cytokeratin, Epstein-Barr virus [EBV]-encoded small RNA-in situ hybridization

4 [EBER-ISH], Ki-67, and p53) for p16-negative uterine cervical SCCs. 
1 Materials and Methods

2 1. Patient selection of p16-negative uterine cervical SCC

3 Five cases of p16-negative uterine cervical SCCs were selected by

4 immunohistochemical staining of p16 (CINtec Histology Kit, clone E6H4;

5 Roche-Mtm-Laboratories, Heidelberg, Germany) from among 107 hysterectomy

6 cases treated at Kyoto University Hospital between January 2010 and December

7 2015. When continuous strong nuclear or nuclear plus cytoplasmic staining of p16

8 was observed in most tumor cells (over $90 \%$ of tumor cells), we labeled the tumor as

9 p16-positive (block-positive). Non-block-positive cases were defined as p16-negative.

10 In well-differentiated, keratinizing cases, p16 positivity was defined as continuous

11 strong staining of the basal cell layer with extension upwards involving at least

12 one-third of the epithelial thickness, according to the Lower Anogenital Squamous

13 Terminology project. ${ }^{7}$

14 Clinical parameters were retrieved from the clinical records of the five

15 p16-negative cases. Histological parameters, such as the tumor size, histological

16 subtype, lymphovascular invasion, and pathological TNM classification, were also

17 reviewed.

Approval for this retrospective study was obtained from the Institutional Ethics

19 Committee. Patients signed the "Kyoto University Hospital Informed Consent Form 
1 for the Non-therapeutic Use of Histopathological Materials", and the signed forms

2 have now been added to all electronic health records.

3

$4 \quad$ 2. Immunohistochemical analyses

5 Immunohistochemical staining was performed using formalin-fixed,

6 paraffin-embedded blocks (FFPE). We used p53 (clone DO-7, 1:100; Dako, Glostrup,

7 Denmark), Ki-67 (clone MIB-1, 1:300; Dako), and CK7 (clone OV-TL12/30, 1:300;

8 Dako) as antibodies, and slides were stained with the Ventana BenchMark ULTRA

9 instrument (Ventana Medical Systems, Tucson, AZ, USA) according to the

10 manufacturer's protocol. Positivity for the nuclear expression of p53 and cytoplasmic

11 expression of CK7 was assessed based on the percentage of positive cells. The

12 Ki-67 index was counted in the hot spot area.

14 3. DNA isolation

15 DNA was extracted from FFPE. We used the QIAamp DNA FFPE Tissue kit

16 (QIAGEN, Hilden, Germany) according to the manufacturer's protocol.

4. Detection of HPV infection 
1 HPV genotyping was performed for all p16-negative cases as a routine clinical test for

2 HPV detection. HPV6, 11, 16, 18, 26, 31, 33, 35, 39, 42, 44, 45, 51, 52, 53, 54, 55, 56,

$358,59,61,62,66,68,70,71,73,82,84,90$, and CP6108 were examined by the

4 PCR-reverse sequence specific oligonucleotide (PCR-rSSO) method (LSI Medience

5 Corporation, Tokyo, Japan).

6

7 4-2. L1 gene detection by consensus primer

8 In addition, we also used multiple consensus PCR primers sets to detect the L1 gene.

9 The advantage of consensus primers for the HPV L1 gene region is that they can

10 detect a large number of HPVs of both known or unknown types, although they can

11 also cause false negatives because of the loss of the $L 1$ open reading frame during

12 integration of viral DNA into the host genome. ${ }^{3,} 16$ Eight primers-My09

13 (5'-CGTCCMARRGGAWACTGATC-3'), My11

14 (5'-GCMCAGGGWCATAAYAATGG-3'), Gp5 (5'-TTTGTTACTGTGGTAGATAC-3'),

$15 \quad$ Gp6

(5'-GAAAAATAAACTGTAAATCA-3'),

Gp5+

16 (5'-TTTGTTACTGTGGTAGATACTAC-3'),

Gp6+

17 (5'-GAAAAATAAACTGTAAATCATATTC-3'),

Oli-1b

(5'-TGYAAATATCCWGATTATWT-3'),

and

Oli-2i

19 (5'-GTATCIACIACAGTAACAAA-3')—were used. HeLa cells (HPV-positive human 
1 cervical cancer cells) and HMC1 (a human mastocytosis cell line) cells were used as

2 positive and negative controls, respectively. The PCR mix consisted of $1 \mu \mathrm{L}$ of DNA

3 (cases 2, 4 and 5, positive control, or negative control), $2 \mu \mathrm{L}$ of each primer pair

4 (My09/My11, Gp5/Gp6, GP5+/Gp6+, and Oli-1b/Oli-2i) and $17 \mu \mathrm{L}$ of Platinum ${ }^{\circledR}$ Blue

5 PCR Supermix (ThermoFisher Scientific, Waltham, MA, USA). The PCR program

6 was $94{ }^{\circ} \mathrm{C}$ for $5 \mathrm{~min},\left(94^{\circ} \mathrm{C}\right.$ for $30 \mathrm{~s}, 45^{\circ} \mathrm{C}$ for $30 \mathrm{~s}$, and $72{ }^{\circ} \mathrm{C}$ for $\left.60 \mathrm{~s}\right)$ for 65 cycles

7 and $72{ }^{\circ} \mathrm{C}$ for 5 min. ${ }^{17} \mathrm{PCR}$ products were examined as described above.

8

9 5. Analyses of CDKN2A

5-1. Bisulfite modification and methylation-specific polymerase chain reaction (MSPCR)

12 DNA methylation patterns in the CpG islands of the CDKN2A were detected by the MSPCR technique, as described previously. ${ }^{18}$ Bisulfite modification of DNA was

14 performed before MSPCR using the MethylEasy ${ }^{\mathrm{TM}}$ Xceed Rapid DNA Bisulphite Modification Kit (Genetic Signatures, Sydney, Australia) according to the manufacturer's protocol. Then, $4 \mu \mathrm{L}$ of modified DNA sample (cases 1-5, Hela, or

$17 \mathrm{HMC} 1)$ and $16 \mu \mathrm{L}$ of PCR mix $\left(14 \mu \mathrm{L}\right.$ of Platinum ${ }^{\circledR}$ Blue PCR Supermix and $1 \mu \mathrm{L}$ of each primer pair) were used for polymerase chain reaction (PCR). The primers were 
1 reverse (5'-GACCCCGAACCGCGACCGTAA-3'), p16-unmethylated (p16-U) forward

2 (5'-TTATTAGAGGGTGGGGTGGATTGT-3'), and p16-U reverse

3 (5'-CAACCCCAAACCACAACCATAA-3'). The PCR program for unmethylated

4 primers was $94{ }^{\circ} \mathrm{C}$ for $5 \mathrm{~min}$, $\left(94^{\circ} \mathrm{C}\right.$ for $30 \mathrm{~s}, 58^{\circ} \mathrm{C}$ for $30 \mathrm{~s}$, and $72{ }^{\circ} \mathrm{C}$ for $30 \mathrm{~s}$ ) for 48

5 cycles and $72{ }^{\circ} \mathrm{C}$ for $4 \mathrm{~min}$. The annealing temperature was changed from $58{ }^{\circ} \mathrm{C}$ to

$6 \quad 67{ }^{\circ} \mathrm{C}$ when using methylated primers. PCR products were verified by $2 \%$ agarose gel

7 electrophoresis, stained with ethidium bromide, and examined under ultraviolet

8 illumination. We used All-purpose Hi-Lo DNA marker (Bionexus, Oakland, CA, USA)

9 to estimate the band size for electrophoresis.

10

$11 \quad$ 5-2. Fluorescence in situ hybridization (FISH)

12 We performed dual-color FISH using commercial probes, including the Spectrum

13 Orange-labeled locus specific p16 (9q21) probe and the Spectrum Green-labeled

14 chromosome 9 centromeric probe (Vysis LSI p16 (CDKN2A) SpectrumOrange/CEP9

15 SpectrumGreen Probe; Abbott Molecular, Des Plaines, IL, USA), according to the

16 manufacturer's protocol.

6. Detection of EBV 
1 We assessed the presence of EBV by EBER-ISH, and the EBV latency pattern was

2 determined by the immunohistochemical analysis for latent membrane protein (LMP)

31 and EBV nuclear antigen (EBNA) 2. EBER-ISH (Ventana Medical Systems) was

4 performed with a BOND-III Fully Automated IHC and ISH Stainer (Leica Biosystems,

5 Nussloch, Germany). We used LMP1 (clone CS-1-4, 1:50; Dako) and EBNA2 (clone

6 PE2, 1:30; Dako) with the Ventana BenchMark ULTRA instrument (Ventana Medical

7 Systems) for these assessments.

8

9 7. Analysis of TP53 mutations

10 The presence of TP53 mutations was examined in Exon 4-9 with direct sequencing

11 using FFPE (LSI Medience Corporation). The reference sequence was NG_017013.2.

12 Both the tumor and non-tumor areas of all the five p16-negative cases were

13 examined. 


\section{Results}

2 1. Clinicopathological features of p16-negative uterine cervical SCC

3 Five (4.7\%) of 107 cases of uterine cervical SCCs showed non-block positivity for p16.

4 The positivity rates of p16 were $5 \%$ (case 1), less than $5 \%$ (case 3 ), and $0 \%$ (cases 2 ,

54 and 5). The clinicopathological characteristics of the p16-negative cases are

6 summarized in Table 1, and representative microscopic images are shown in Figure 1.

7 All patients had a reproductive history. Three of the five p16-negative cases were

8 non-keratinizing SCC (cases 1 to 3), and two were keratinizing SCC (cases 4 and 5).

9 All cases had SILs, and the area was p16-negative, in addition to the invasive area.

10 Case 2 had a sarcomatous component at recurrence. All cases had lymphovascular

11 invasion at the time of surgery.

Case 3 showed an impressive clinical course and morphological features. ${ }^{19}$

13 This patient had a history of cervical intraepithelial neoplasia (CIN) 1-2 and had

14 received a cytological diagnosis of $\mathrm{ASC}-\mathrm{H}$ (atypical squamous cells, cannot exclude

15 high grade SIL) two years before the definitive diagnosis. She underwent a follow-up

16 cervical biopsy, and the diagnosis was p16-negative CIN3/HSIL. A Loop

17 Electrosurgical Excision Procedure (LEEP) was performed for this lesion. The LEEP

18 specimen had a well-differentiated squamous epithelium with papillary and 
1 specimens showed positive margin, and the followed hysterectomy was performed.

2 The specimen had invasive non-keratinizing SCC beneath the condylomatous

3 component (Figure 2c). p16 was negative both in the condylomatous and

4 non-keratinizing SCC components (Figure 2e and 2i). She died of multiple lung

5 metastasis about two years after hysterectomy.

6

7 2. HPV infection status

8 HPV-genotyping by PCR-rSSO revealed that case 1 had HPV56, which is known to

9 be a high-risk HPV; case 3 had HPV6, which is known to be a low-risk HPV; and

10 cases 2, 4, and 5 did not show any HPV infection. Using multiple consensus primer

11 sets, the L1 gene was detected in case 2 by the My09/My11 primer set (Figure 3).

13 3. CDKN2A gene status

14 To explore the mechanism underlying the p16-negative staining, we examined the

15 status of the CDKN2A gene coding p16, including the methylation status and deletion

16 status. Case 1 had a methylated band, and case 2 had both methylated and

17 unmethylated DNA bands. Cases 3 and 4 had unmethylated bands. Case 5 had 18 neither methylated nor unmethylated bands and was not analyzed (Figure 4a). We 
1 found that case 4 had a homozygous deletion of CDKN2A according to a dual-color

2 FISH analysis (Figure 4b).

3

4

4. Analyses of other factors

5 Case 1 showed positivity for EBER-ISH and LMP1 (Figure 5a), while EBNA2 was

6 negative. The other four cases were all negative. Case 2 had a nonsense mutation at

7 exon 6 of TP53 (c.637C>T: p.Arg213Ter) (Figure 5b). The DNA sample of case 5 was

8 not suitable for TP53 mutation analyses. CK7 was negative in cases 1, 2 and 4

9 (0\%-1\%), but focally positive in cases 3 and 5 (30\% and 60\%, respectively). 
1

\section{Discussion}

2 We found five cases of p16-negative cervical SCCs, and the combination of several

3 mechanisms, including the absence of high-risk HPV infection (cases 3 to 5), the

4 presence of low-risk HPV infection (case 3), the methylation of CDKN2A (cases 1 and

5 2), homozygous deletion of CDKN2A (case 4) and EBV infection (case 1), was

6 implied. A TP53 mutation was found in the case infected by HPV with an unknown

7 genotype (case 2).

8 Most cervical SCCs are positive for p16, and our search of the literature

9 showed that the frequency of p16-negative cervical SCCs ranged from $0 \%$ to $16.5 \%{ }^{8}$,

109 In the present study, the frequency was $4.7 \%(5 / 107)$, which was similar to the

11 findings in the previous studies. To our knowledge, there have been 6 reports

12 regarding 16 cases describing the morphology and HPV infection status of

13 p16-negative SCCs (Table 2). ${ }^{10-15}$ Some unique morphologies mimicking giant

14 immature condyloma and papillary SIL were reported by Tsai et al. and Liu et al. ${ }^{12,15}$

15 In our study, we found two unique morphologies in SCCs that included a

16 condylomatous component and sarcomatous component. HPV infection was

17 detected in four of 16 cases (25.0\%) in the previous reports, while we found HPV

18 infection in three of five cases (60.0\%). The method of detecting HPV has varied, and 
1 the combination of type-specific PCR and multiple consensus primer sets for the L1

2 gene is ideal for the thorough examination of HPV infection. ${ }^{17,} 20$

One of our cases had low-risk HPV infection. The mechanism behind carcinogenesis with low-risk HPVs is unclear, but some cervical SCCs are reported to

5 have an association with low-risk HPVs. ${ }^{15,21}$ Liu et al. reported three cases of p16

6 negative HPV6-associated HSIL/SCCs in the uterine cervix. ${ }^{15}$ Guimera et al. reported

79 cases of cervical SCCs with low-risk HPVs. ${ }^{21}$ In a previous report by Sanjose et al.,

8 a single low-risk HPV infection was detected in $0.18 \%$ of cervical SCCs (16/8977). ${ }^{22}$

The abnormal status of CDKN2A was determined to be one reason for p16

10 negativity. p16 is encoded by the CDKN2A tumor suppressor gene. p16 product

11 inhibits G1-S progression by preventing phosphorylation of the RB protein and

12 preventing activation of transcription factor, E2F1, which leads to an uncontrollable

13 cell cycle. Therefore, loss of the CDKN2A function because of promoter

14 hypermethylation or deletion results in RB protein phosphorylation and carcinogenesis. ${ }^{23}$ In head and neck SCCs, over half of HPV-negative SCCs were

16 found to have alterations of $C D K N 2 A .{ }^{24}$ Regarding the uterine cervix, Nakashima et al.

17 reported that one out of 27 cervical SCCs had hypermethylation of CDKN2A, and four

18 out of 35 cervical SCCs had a homozygous deletion of CDKN2A. ${ }^{25}$ Although the 
1 controversial in uterine cervical SCC, ${ }^{26-28}$ in a meta-analysis including 26 studies, its

2 correlation with the pathogenesis was indicated. ${ }^{29}$ In our study, hypermethylation of

3 CDKN2A was identified in two cases: one with HPV56 infection, and the other with

4 HPV infection of unknown genotype. A homozygous deletion was detected in one

5 case without HPV infection. The association between the methylation status of

6 CDKN2A, p16 expression, and HPV infection is inconsistent, $26,30,31$ and further

$7 \quad$ studies are required.

8 Co-infection of EBV and HPV in uterine cervical SCCs was also reported. 32,33

9 In EBV-associated gastric carcinoma, promoter hypermethylation of various

10 tumor-related genes, including $C D K N 2 A$, has been identified..$^{34,35}$ In our study of case

11 1, which had an EBV infection, hypermethylation of CDKN2A was noted. Furthermore,

12 in a previous study, Ohtani et al. showed that LMP1 blocks the p16-RB pathway and

13 represses the p16 expression. ${ }^{36}$ In our study, case 1 was infected by EBV and

14 showed latency status II (positive for LMP1 and negative for EBNA2). This may be an additional reason why p16 was negative in case 1.

In addition to HPV infection, we also examined the TP53 mutation status as

17 another etiologic factor. One report found that all cases of HPV-negative SCC had overexpression of p53. ${ }^{13}$ In another report, TP53 mutations were found in $16 \%$ of 
1 frequency between HPV-positive and HPV-negative samples. ${ }^{37}$ In our study, two of

2 five p16-negative SCCs showed p53 overexpression; one case had low-risk HPV,

3 and the other case did not have an HPV infection. In the low-risk HPV case, the

4 overexpression of p53 was focal. Furthermore, one nonsense mutation in TP53

5 (c.637C>T: p.Arg213Ter) was detected in the tumor area of case 2. The mutant T

6 peak of codon 637 was relatively low, and there is a possibility that this mutation is

7 subclonal and that background wild-type cells are included. This mutation was

8 previously identified in several reports on malignant tumors of female reproductive

9 organs with sarcomatous component. ${ }^{38,39}$ However, in those previous reports, the

10 p53 immunoexpression showed a null pattern, while that in case 2 in our study

11 showed a wild pattern. Therefore, the utility of p53 expression for diagnosing

12 p16-negative cervical SCCs remains unclear.

We were unable to determine the reason for the negative p16 expression in

14 case 5. The specimen of case 5 was fixed with re-used formalin, which may have

resulted in an unstable formalin concentration, as 10\% buffered formalin was used in

the other 4 cases. Therefore, inappropriate fixation for the genome analysis may have

caused our failure to detect HPV infection and methylation of CDKN2A in case 5.

19 CIN, the p16 expression was shown to be not only a diagnostic tool but also a 
1 prognostic factor. p16 block-positive CIN1 cases have a higher tendency to progress

2 to HSIL than p16-negative cases. ${ }^{40,41}$ For CIN2, p16-negative CIN2 shows a higher

3 rate of regression than p16-positive cases, and the p16 expression is an important

4 marker for clinical management. ${ }^{42}$ For carcinoma, p16-negative SCCs have a poor

5 prognosis compared to p16-positive cases. In a report by Masoudi et al. on 115

6 cervical SCC cases, a negative p16 expression was correlated with a lower

7 disease-free survival according to a univariate analysis. ${ }^{8}$ Putte et al. studied 220

8 cervical SCCS and found that a low expression of p16 was significantly related to a

9 decreased overall survival. ${ }^{43}$ Our data were too few to compare with p16-positive

10 cases, so a further investigation is required.

11 Uterine cervical SCCs with low-grade atypia are difficult to diagnose from a

12 biopsy. The differential diagnosis includes a wide spectrum of cervical disease, from

13 non-neoplastic lesions to malignant lesions. Histological findings, such as mild

14 cytological atypia, a low mitotic index, and a low Ki-67 index, are evidence suggesting

15 non-neoplastic lesions. ${ }^{44}$ Diffuse block-positive p16 indicates high-risk HPV infection,

16 although p16-negative cervical SCCs do exist. Tsai's report presented a warning

17 case of cervical SCC mimicking immature condyloma without p16 expression. ${ }^{12}$ Liu et

18 al. and Guimera et al. also showed impressive findings that p16-negative 
1 SIL or well-differentiated morphology according to a histological examination. ${ }^{15,21}$ Our

2 case 3 was similar to these previously reported cases. These findings suggest that

3 cervical SCCs with low-risk HPVs show a well-differentiated morphology and are

4 difficult to diagnose. Liu et al. indicated that nuclear overlap, variable nuclear density

5 throughout the epithelium and anisokaryosis were more frequent in HSIL/carcinoma

6 than LSIL/immature condyloma. In addition, while the Ki-67 expression is seen in

7 over $75 \%$ of epithelial cells in carcinomas, its expression is concentrated in the basal

8 third of the epithelium in LSIL/immature condyloma. ${ }^{15}$ In such cases, CK7 can be

9 another marker for HPV infection. CK7 contributes to viral episomal replication in

10 high-risk HPV infected cells, ${ }^{45}$ and CIN1 with CK7 expression is correlated with CIN2

11 progression. ${ }^{46}$ However, we found no association between the CK7 expression and

12 HPV infection in the present study.

In conclusion, the mechanism underlying the p16-negativity in uterine cervical

14 SCCs was heterogeneous, involving the absence of a high-risk HPV infection, the presence of a low-risk HPV infection, CDKN2A gene methylation or deletion, and co-infection of EBV. Another point to be noted concerning p16-negative cases is that

17 a low-grade/condylomatous appearance seen in some cases, which may confound the diagnosis. 


\section{Acknowledgements}

2 The authors would like to thank Ayako Furuhata, Chiyuki Ueshima and Masahiro

3 Hirata for their technical assistance.

4

5 Disclosure Statement

$6 \quad$ None declared.

7

\section{Author contributions}

9 MR-K, SM and TK designed the study. MR-K and TK performed the experiments. KA

10 and $\mathrm{MM}$ provided clinical information. MR-K and SM wrote the manuscript. $\mathrm{HH}$

11 supervised the study. All authors approved the final manuscript. 


\section{References}

21 Li N, Franceschi S, Howell-Jones R, Snijders PJ, Clifford GM. Human

3 papillomavirus type distribution in 30,848 invasive cervical cancers worldwide:

4 Variation by geographical region, histological type and year of publication. Int $J$

$5 \quad$ Cancer. 2011; 128: 927-35.

62 Insinga RP, Liaw KL, Johnson LG, Madeleine MM. A systematic review of

7 the prevalence and attribution of human papillomavirus types among cervical, vaginal,

8 and vulvar precancers and cancers in the United States. Cancer Epidemiol

$9 \quad$ Biomarkers Prev. 2008; 17: 1611-22.

103 Walboomers JM, Jacobs MV, Manos MM, et al. Human papillomavirus is a

11 necessary cause of invasive cervical cancer worldwide. J Pathol. 1999; 189: 12-9.

124 Klaes R, Friedrich T, Spitkovsky D, et al. Overexpression of p16(INK4A) as

13 a specific marker for dysplastic and neoplastic epithelial cells of the cervix uteri. Int J

14 Cancer. 2001; 92: 276-84.

155 Mendenhall WM, Logan HL. Human papillomavirus and head and neck

16 cancer. Am J Clin Oncol. 2009; 32: 535-9.

176 Li Y, Nichols MA, Shay JW, Xiong Y. Transcriptional repression of the

18 D-type cyclin-dependent kinase inhibitor p16 by the retinoblastoma susceptibility 19 gene product pRb. Cancer Res. 1994; 54: 6078-82. 
17 Darragh TM, Colgan TJ, Thomas Cox J, et al. The Lower Anogenital

2 Squamous Terminology Standardization project for HPV-associated lesions:

3 background and consensus recommendations from the College of American

4 Pathologists and the American Society for Colposcopy and Cervical Pathology. Int J

5 Gynecol Pathol. 2013; 32: 76-115.

68 Masoudi H, Van Niekerk DJ, Gilks CB, et al. Loss of p16 INK4 expression in

7 invasive squamous cell carcinoma of the uterine cervix is an adverse prognostic

8 marker. Histopathology. 2006; 49: 542-5.

99 Klaes R, Benner A, Friedrich T, et al. p16INK4a immunohistochemistry 10 improves interobserver agreement in the diagnosis of cervical intraepithelial 11 neoplasia. Am J Surg Pathol. 2002; 26: 1389-99.

1210 Agoff SN, Lin P, Morihara J, Mao C, Kiviat NB, Koutsky LA. p16(INK4a)

13 expression correlates with degree of cervical neoplasia: a comparison with Ki-67

14 expression and detection of high-risk HPV types. Mod Pathol. 2003; 16: 665-73.

1511 Volgareva G, Zavalishina L, Andreeva Y, et al. Protein p16 as a marker of 16 dysplastic and neoplastic alterations in cervical epithelial cells. BMC Cancer. 2004; 4:

1758. 
112 Tsai $\mathrm{KH}$, Kuo KT, Chen $\mathrm{CH}$, Lin $\mathrm{HH}$. Non HPV-related cervical squamous

2 cell carcinoma with unusual histologic characteristics mimicking a giant immature

3 condyloma: a case report. J Clin Pathol. 2013; 66: 823-5.

413 Rodriguez-Carunchio L, Soveral I, Steenbergen RD, et al. HPV-negative

5 carcinoma of the uterine cervix: a distinct type of cervical cancer with poor prognosis.

6 BJOG. 2015; 122: 119-27.

714 Nicolas I, Marimon L, Barnadas E, et al. HPV-negative tumors of the uterine

8 cervix. Mod Pathol. 2019; 32: 1189-96.

915 Liu MZ, Hung YP, Huang EC, Howitt BE, Nucci MR, Crum CP. HPV

10 6-associated HSIL/Squamous Carcinoma in the Anogenital Tract. Int J Gynecol

11 Pathol. 2019; 38: 493-97.

1216 Depuydt CE, Boulet GA, Horvath CA, Benoy IH, Vereecken AJ, Bogers JJ.

13 Comparison of MY09/11 consensus PCR and type-specific PCRs in the detection of

14 oncogenic HPV types. J Cell Mol Med. 2007; 11: 881-91.

1517 Karlsen F, Kalantari M, Jenkins A, et al. Use of multiple PCR primer sets for

16 optimal detection of human papillomavirus. J Clin Microbiol. 1996; 34: 2095-100.

1718 Herman JG, Graff JR, Myohanen S, Nelkin BD, Baylin SB.

18 Methylation-specific PCR: a novel PCR assay for methylation status of CpG islands.

19 Proc Natl Acad Sci U S A. 1996; 93: 9821-6. 
119 Masuda M, Abiko K, Minamiguchi S, Murakami R, Baba T, Konishi I. Case of

2 rapidly progressing condylomatous squamous cell carcinoma of the uterine cervix

3 associated with low-risk human papillomavirus type 6. J Obstet Gynaecol Res. 2018;

4 44: 583-87.

520 Husnjak K, Grce M, Magdic L, Pavelic K. Comparison of five different

6 polymerase chain reaction methods for detection of human papillomavirus in cervical

7 cell specimens. J Virol Methods. 2000; 88: 125-34.

821 Guimera N, Lloveras B, Lindeman J, et al. The occasional role of low-risk

9 human papillomaviruses $6,11,42,44$, and 70 in anogenital carcinoma defined by 10 laser capture microdissection/PCR methodology: results from a global study. Am J

11 Surg Pathol. 2013; 37: 1299-310.

1222 de Sanjose S, Quint WG, Alemany L, et al. Human papillomavirus genotype

13 attribution in invasive cervical cancer: a retrospective cross-sectional worldwide study.

14 Lancet Oncol. 2010; 11: 1048-56.

1523 Zhao R, Choi BY, Lee MH, Bode AM, Dong Z. Implications of Genetic and

16 Epigenetic Alterations of CDKN2A (p16(INK4a)) in Cancer. EBioMedicine. 2016; 8:

$17 \quad 30-39$. 
124 Chung $\mathrm{CH}$, Guthrie VB, Masica DL, et al. Genomic alterations in head and

2 neck squamous cell carcinoma determined by cancer gene-targeted sequencing. Ann

3 Oncol. 2015; 26: 1216-23.

$425 \quad$ Nakashima R, Fujita M, Enomoto T, et al. Alteration of p16 and p15 genes in

5 human uterine tumours. Br J Cancer. 1999; 80: 458-67.

626 Carestiato FN, Afonso LA, Moyses N, Almeida Filho GL, Velarde LG,

7 Cavalcanti SM. An upward trend in DNA p16ink4a methylation pattern and high risk

8 HPV infection according to the severity of the cervical lesion. Rev Inst Med Trop Sao

9 Paulo. 2013; 55: 329-34.

1027 Blanco-Luquin I, Guarch $\mathrm{R}$, Ojer $\mathrm{A}$, et al. Differential role of gene

11 hypermethylation in adenocarcinomas, squamous cell carcinomas and cervical

12 intraepithelial lesions of the uterine cervix. Pathol Int. 2015; 65: 476-85.

1328 Banzai C, Nishino K, Quan J, et al. Promoter methylation of DAPK1, FHIT,

14 MGMT, and CDKN2A genes in cervical carcinoma. Int J Clin Oncol. 2014; 19: 127-32.

1529 Li J, Zhou C, Zhou H, et al. The association between methylated CDKN2A

16 and cervical carcinogenesis, and its diagnostic value in cervical cancer: a

17 meta-analysis. Ther Clin Risk Manag. 2016; 12: 1249-60. 
130 Lin Z, Gao M, Zhang X, et al. The hypermethylation and protein expression

2 of p16 INK4A and DNA repair gene O6-methylguanine-DNA methyltransferase in

3 various uterine cervical lesions. J Cancer Res Clin Oncol. 2005; 131: 364-70.

431 Dong SM, Kim HS, Rha SH, Sidransky D. Promoter hypermethylation of

5 multiple genes in carcinoma of the uterine cervix. Clin Cancer Res. 2001; 7: 1982-6.

632 Khenchouche A, Sadouki N, Boudriche A, et al. Human papillomavirus and

7 Epstein-Barr virus co-infection in cervical carcinoma in Algerian women. Virol J. 2013;

8 10: 340.

933 Sasagawa T, Shimakage M, Nakamura M, Sakaike J, Ishikawa H, Inoue M.

10 Epstein-Barr virus (EBV) genes expression in cervical intraepithelial neoplasia and

11 invasive cervical cancer: a comparative study with human papillomavirus (HPV)

12 infection. Hum Pathol. 2000; 31: 318-26.

1334 Sakuma K, Chong JM, Sudo M, et al. High-density methylation of p14ARF

14 and p16INK4A in Epstein-Barr virus-associated gastric carcinoma. Int $\mathrm{J}$ Cancer.

$15 \quad 2004 ; 112: 273-8$.

1635 Shinozaki-Ushiku A, Kunita A, Fukayama M. Update on Epstein-Barr virus

17 and gastric cancer (review). Int J Oncol. 2015; 46: 1421-34. 
136 Ohtani N, Brennan P, Gaubatz S, et al. Epstein-Barr virus LMP1 blocks

2 p16INK4a-RB pathway by promoting nuclear export of E2F4/5. J Cell Biol. 2003; 162:

$3 \quad 173-83$.

437 Tornesello ML, Annunziata C, Buonaguro L, Losito S, Greggi S, Buonaguro

5 FM. TP53 and PIK3CA gene mutations in adenocarcinoma, squamous cell carcinoma

6 and high-grade intraepithelial neoplasia of the cervix. J Trans/ Med. 2014; 12: 255.

738 Ardighieri L, Mori L, Conzadori S, et al. Identical TP53 mutations in pelvic

8 carcinosarcomas and associated serous tubal intraepithelial carcinomas provide

9 evidence of their clonal relationship. Virchows Arch. 2016; 469: 61-9.

1039 Hodgson A, Amemiya Y, Seth A, Djordjevic B, Parra-Herran C. High-grade

11 Mullerian Adenosarcoma: Genomic and Clinicopathologic Characterization of a

12 Distinct Neoplasm With Prevalent TP53 Pathway Alterations and Aggressive

13 Behavior. Am J Surg Pathol. 2017; 41: 1513-22.

1440 del Pino M, Garcia S, Fuste V, et al. Value of p16(INK4a) as a marker of 15 progression/regression in cervical intraepithelial neoplasia grade 1. Am J Obstet 16 Gynecol. 2009; 201: 488 e1-7.

1741 Cortecchia S, Galanti G, Sgadari C, et al. Follow-up study of patients with 18 cervical intraepithelial neoplasia grade 1 overexpressing p16Ink4a. Int J Gynecol 19 Cancer. 2013; 23: 1663-9. 
142 Miralpeix E, Genoves J, Maria Sole-Sedeno J, et al. Usefulness of

2 p16(INK4a) staining for managing histological high-grade squamous intraepithelial

3 cervical lesions. Mod Pathol. 2017; 30: 304-10.

443 van de Putte G, Holm R, Lie AK, Trope CG, Kristensen GB. Expression of

5 p27, p21, and p16 protein in early squamous cervical cancer and its relation to

6 prognosis. Gynecol Oncol. 2003; 89: 140-7.

744 Kalof AN, Cooper K. Our approach to squamous intraepithelial lesions of the

8 uterine cervix. J Clin Pathol. 2007; 60: 449-55.

945 Lee H, Lee H, Cho YK. Cytokeratin7 and cytokeratin19 expression in high

10 grade cervical intraepithelial neoplasm and squamous cell carcinoma and their

11 possible association in cervical carcinogenesis. Diagn Pathol. 2017; 12: 18.

1246 Mills AM, Paquette C, Terzic T, Castle PE, Stoler MH. CK7

13 Immunohistochemistry as a Predictor of CIN1 Progression: A Retrospective Study of

14 Patients From the Quadrivalent HPV Vaccine Trials. Am J Surg Pathol. 2017; 41:

$15 \quad 143-52$. 


\section{$1 \quad$ Figure legends}

2 Figure 1. Representative pathological findings of five p16-negative SCCs. (a-e)

3 Cases 1 to 3 were non-keratinizing SCC, and cases 4 and 5 were keratinizing SCC.

4 Case 2 had a sarcomatous component. (f-j) p16 was negative in every case. (k-o) In

5 Case 3, p53 was overexpressed in the hot spot (50\%-60\%). Case 5 showed p53

6 overexpression. (p-t) The Ki-67 index of case 5 was low $(<5 \%)$.

8 Figure 2. Representative pathological findings of case 3. (a, b) Low-power view

9 of the LEEP specimen. Papillary and condylomatous growth patterns were seen. (c)

10 Low-power view of the hysterectomy specimen. Tumor nests of non-keratinizing SCC

11 (black square ${ }^{\star *}$ ) were observed beneath the condylomatous component (black

12 square*). (d) High magnification of the condylomatous component $\left(^{*}\right)$. (h) High

13 magnification of the non-keratinizing SCC $\left.{ }^{(*}\right)$. (e, i) Both components were negative

14 for p16. (f, j) p53 had wild-type expression in most areas. (g, k) The Ki-67 index was

15 about $30 \%$.

17 Figure 3. PCR for the L1 gene using multiple consensus primer sets. The L1 gene was detected using the My09/My11 PCR primer set in case 2 (M, Molecular weight marker; Number, Case number; NC., Negative control; PC., Positive control). 
2 Figure 4. An analysis of the CDKN2A gene. (a) The methylation status

3 of CDKN2A detected by methylation-specific polymerase chain reaction (Lanes 1-5,

4 Case number; Lane 6, Hela; Lane 7, HMC1; M, Molecular weight marker; Lanes u,

5 reactions using $\mathrm{p} 16-\mathrm{U}$ primers specific for the unmethylated CpG sites; Lanes $\mathrm{m}$,

6 reactions using $\mathrm{p} 16-\mathrm{M}$ primers specific for the methylated CpG sites). (b) The

7 homozygous deletion of CDKN2A (loss of both orange signals) was observed in case

8 4. Normal epithelium had two orange and two green (CEP9) signals (inset: normal 9 epithelium).

11 Figure 5. Inspection results of p16-negative SCCs. (a) EBER-ISH and LMP1 were

12 positive in case 1 (left: EBER-ISH, positive in about $50 \%$ of tumor cells, inset: LMP1).

(b) The TP53 mutation (c.637C>T: p.Arg213Ter) in case 2.

14 
Figure 1

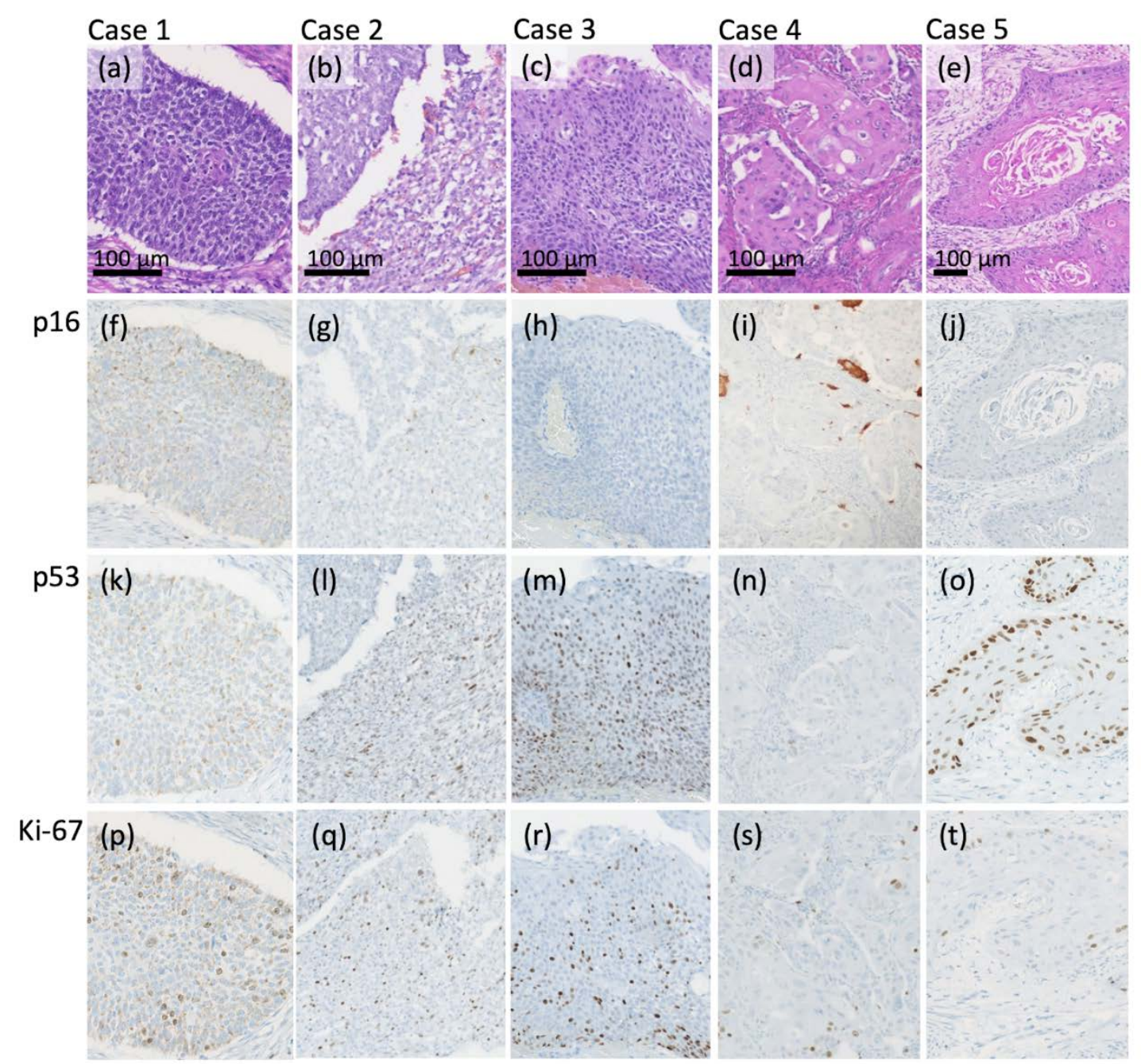


Figure 2
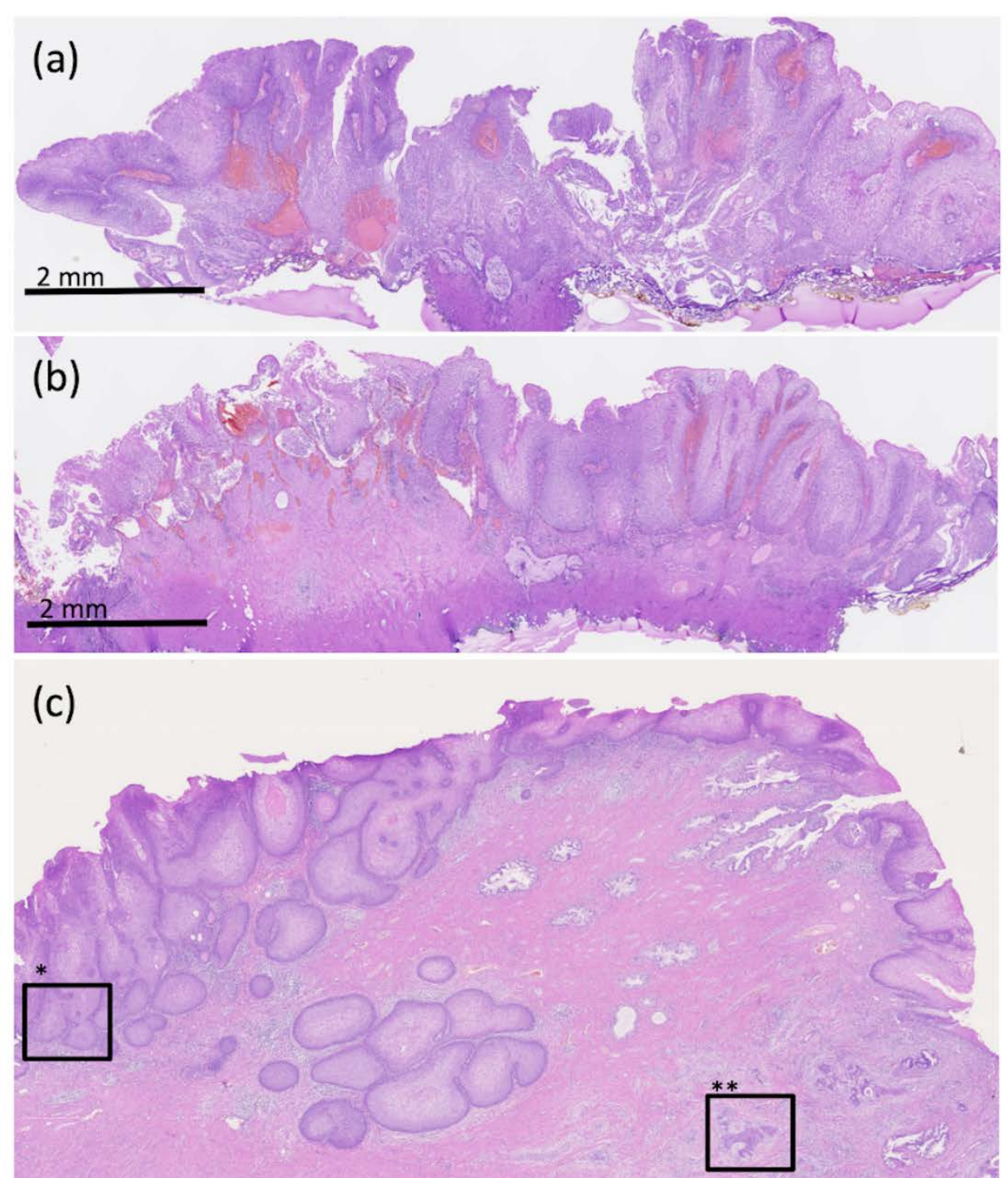

$2 \mathrm{~mm}$

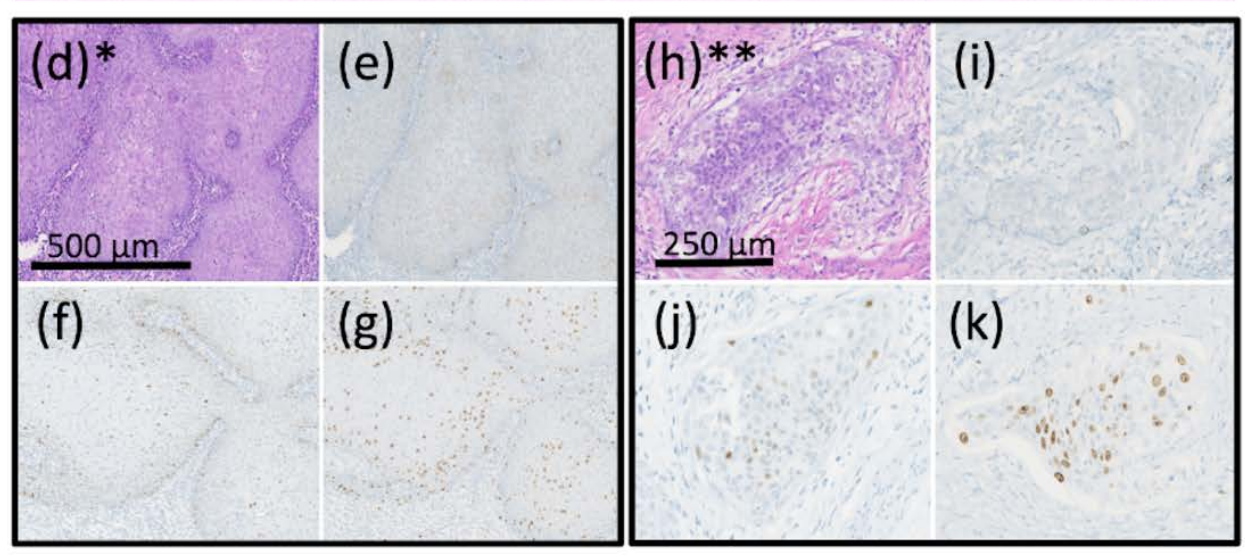


Figure 3

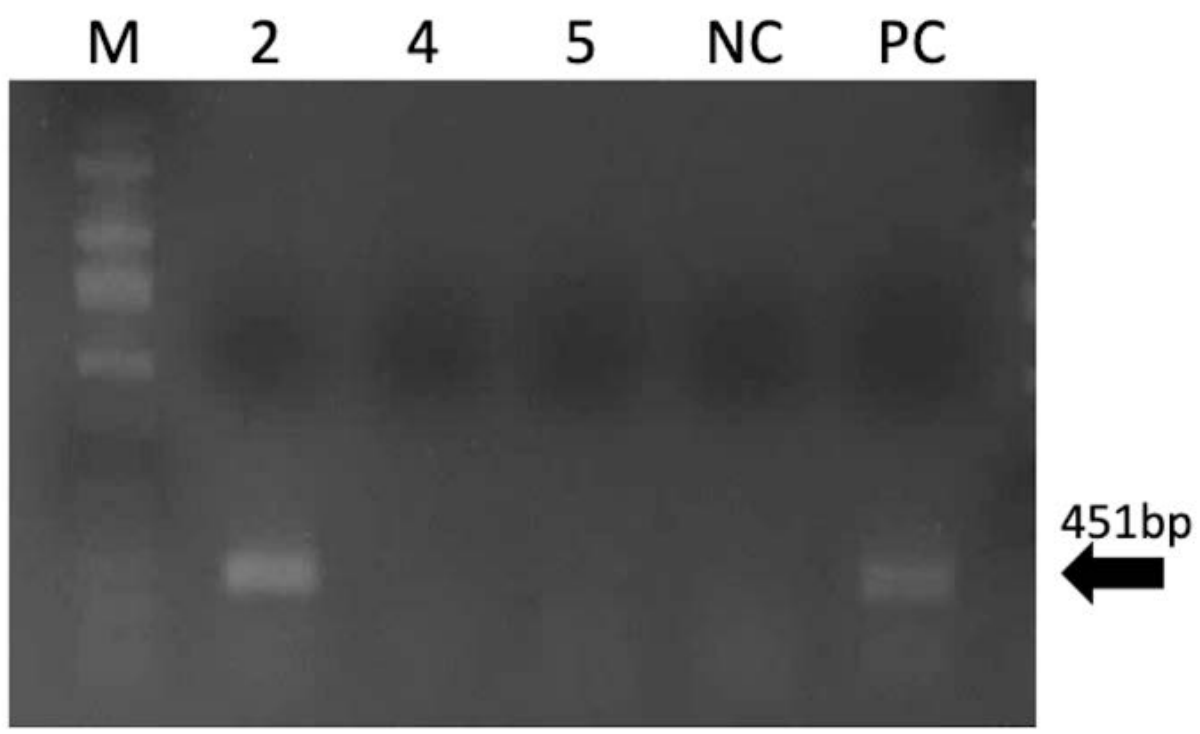


Figure 4

(a)

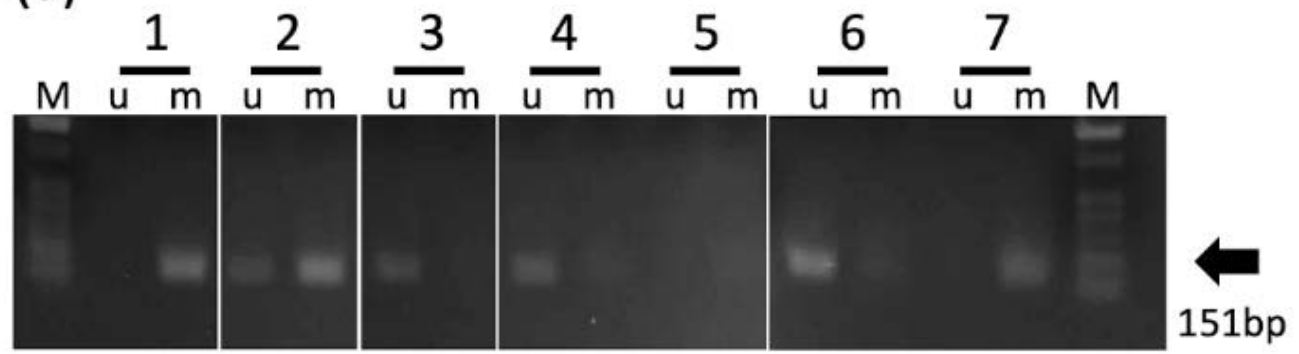

(b)

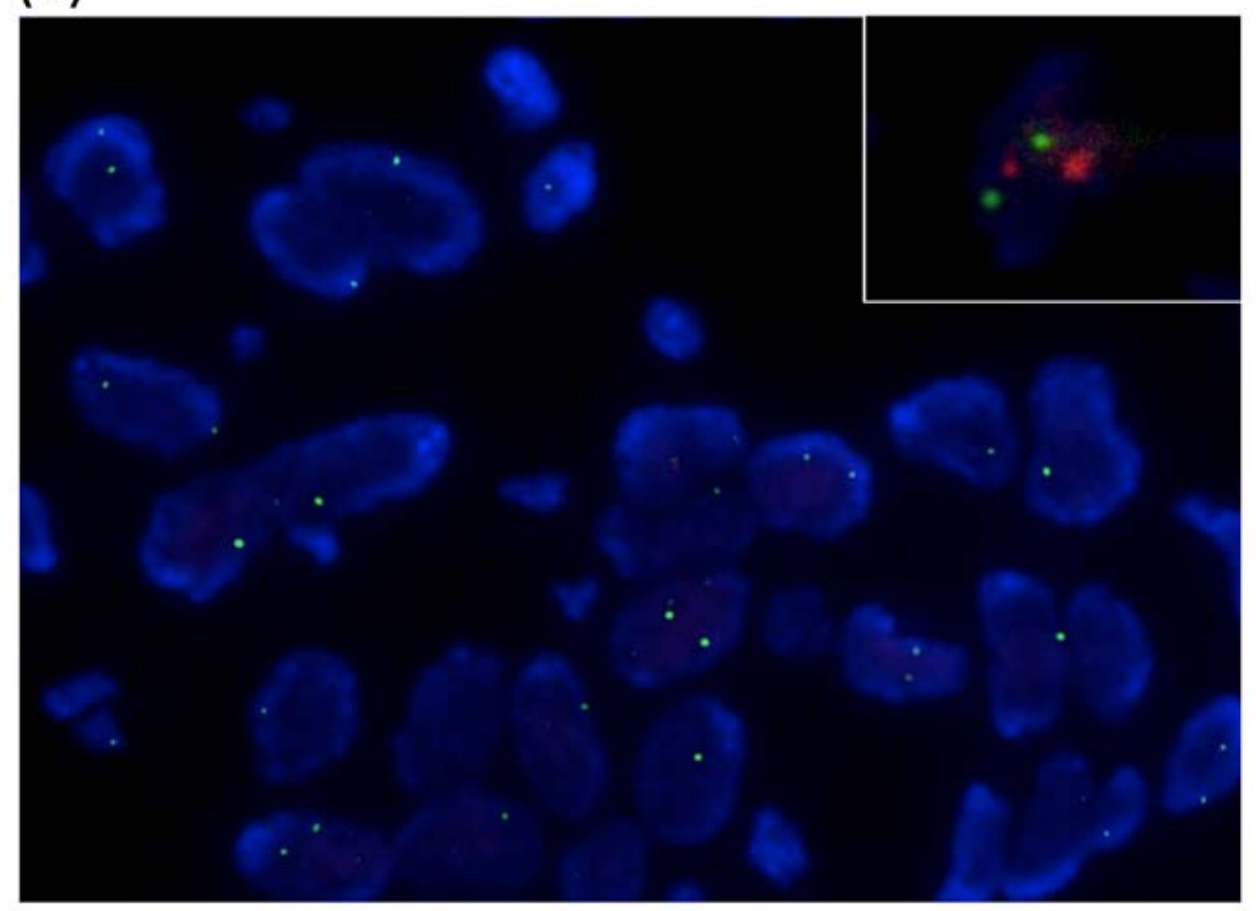


Figure 5

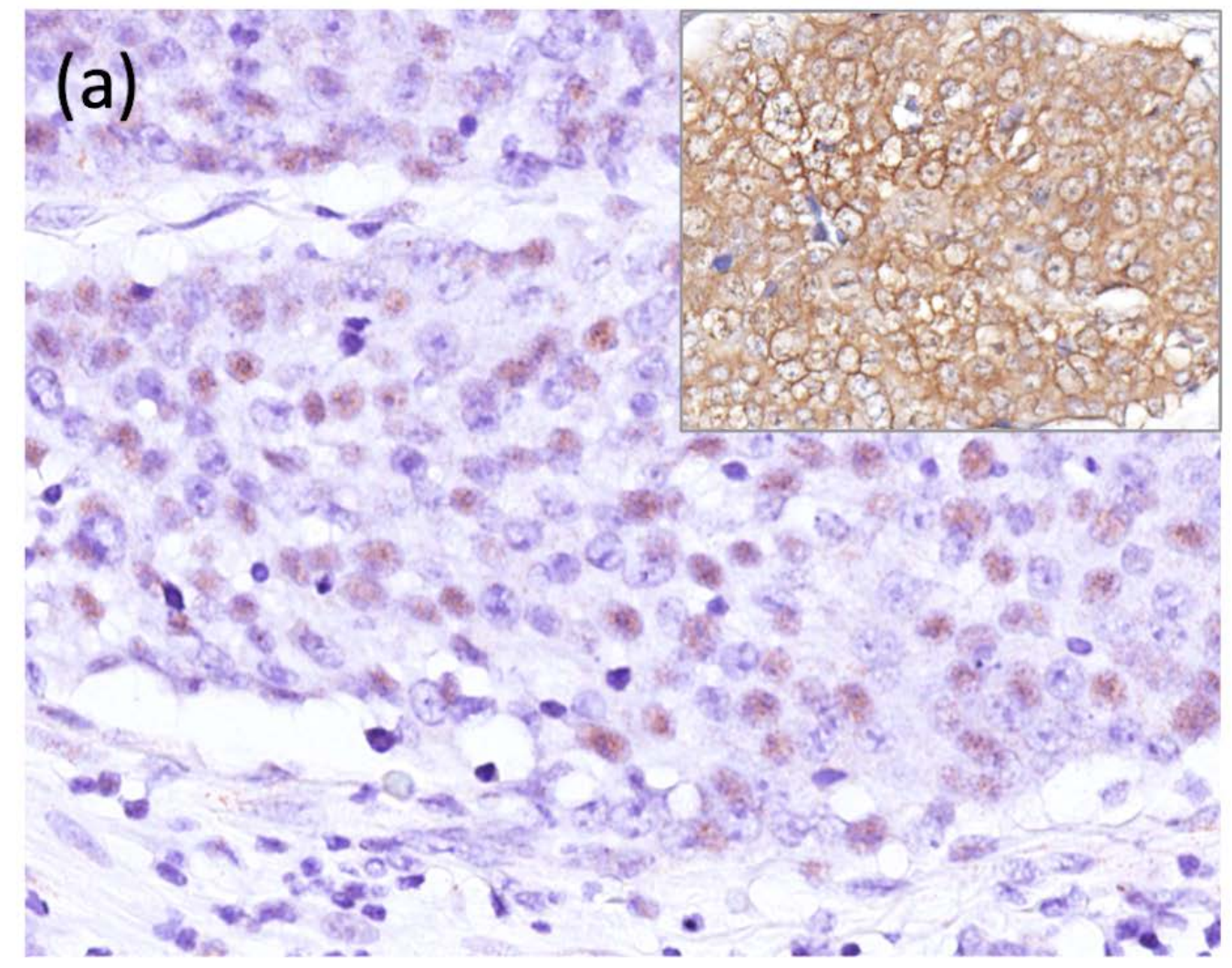

(b)

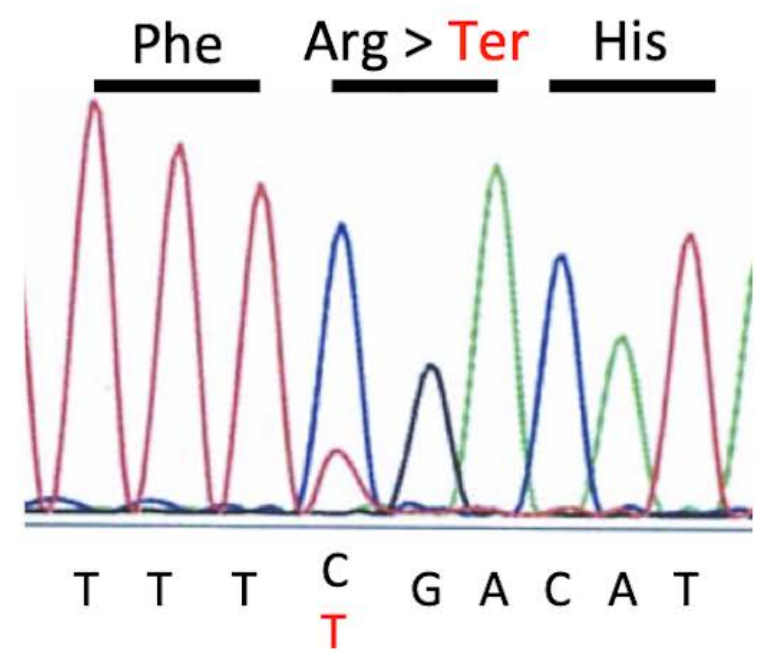

Exon6: c.637C>T: p.Arg213Ter 
Table 1. Clinicopathological features of p16-negative cervical squamous cell carcinoma (SCC)

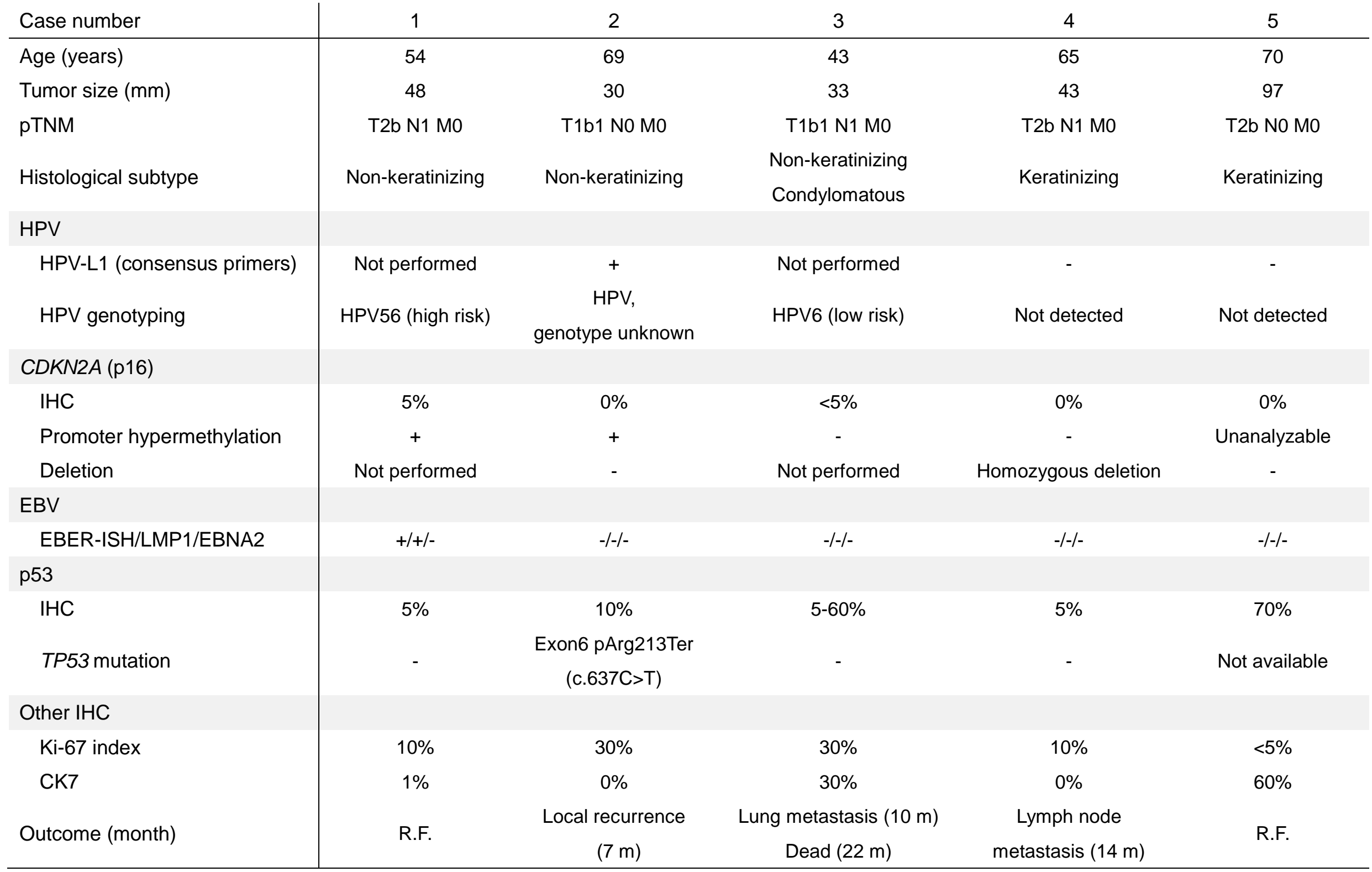

EBV, Epstein-Barr virus; EBER-ISH, EBV-encoded small RNA-in situ hybridization; EBNA2, EBV nuclear antigen 2; HPV, human papilloma virus; IHC, immunohistochemistry; LMP1, latent membrane protein 1; R.F., recurrence-free 
Table 2. Literature review of p16-negative cervical squamous cell carcinoma (SCC) with HPV analyses

\begin{tabular}{|c|c|c|c|c|c|c|c|}
\hline Author & Year & $\begin{array}{l}\text { Total number } \\
\text { of cases }\end{array}$ & Histology (number of cases) & $\begin{array}{l}\text { p16 antibody } \\
\text { clone }\end{array}$ & HPV (number of cases) & $\begin{array}{l}\text { TS- } \\
\text { PCR }\end{array}$ & $\begin{array}{l}\text { Consensus } \\
\text { PCR }\end{array}$ \\
\hline Agoff ${ }^{10)}$ & 2003 & 4 & $\operatorname{SCC}(4)$ & $\mathrm{E} 6 \mathrm{H} 4$ & Negative & Yes & Multiple \\
\hline Volgareva ${ }^{11)}$ & 2004 & 1 & $\operatorname{SCC}(1)$ & $\mathrm{E} 6 \mathrm{H} 4$ & HPV16 (1) & Yes & No \\
\hline Tsai ${ }^{12)}$ & 2013 & 1 & $\begin{array}{l}\text { Mimicking giant immature } \\
\text { condyloma (1) }\end{array}$ & Not available & Negative & No & Single \\
\hline Rodriguez ${ }^{13)}$ & 2015 & 2 & $\begin{array}{l}\text { Keratinizing (1) } \\
\text { Non-keratinizing (1) }\end{array}$ & $\mathrm{E} 6 \mathrm{H} 4$ & Negative & Yes & Single \\
\hline Nicolas ${ }^{14)}$ & 2019 & 5 & $\begin{array}{l}\text { Keratinizing (1) } \\
\text { Non-keratinizing (3) } \\
\text { Sarcomatoid (1) }\end{array}$ & $\mathrm{E} 6 \mathrm{H} 4$ & Negative & Yes & No \\
\hline Liu 15) & 2019 & 3 & Papillary SIL + invasion (3) & $\mathrm{E} 6 \mathrm{H} 4$ & HPV6 (3) & Yes & Multiple \\
\hline Our case & 2019 & 5 & $\begin{array}{l}\text { Non-keratinizing (2) } \\
\text { Non-keratinizing, } \\
\text { condylomatous (1) } \\
\text { Keratinizing (2) }\end{array}$ & $\mathrm{E} 6 \mathrm{H} 4$ & $\begin{array}{l}\text { HPV56 (1) HPV6 (1) } \\
\text { Unknown genotype (1) }\end{array}$ & Yes & Multiple \\
\hline
\end{tabular}

HPV, human papilloma virus; SIL, squamous intraepithelial lesion; TS-PCR, type-specific polymerase chain reaction; 